\title{
LOS SERVICIOS DE PREVENCIÓN DE RIESGOS LABORALES EN TIEMPOS DEL CORONAVIRUS
}

\author{
The occupational risk prevention services in Coronavirus times \\ RubÉn López FernándeZ* \\ Universidad de Murcia, España
}

\begin{abstract}
RESUMEN
La aparición del COVID-19 no solo ha sacudido al mundo del trabajo, sino que trasciende a todas las dimensiones de lo conocido. Cuando apenas se llevan andados dos meses desde que se decretara el estado de alarma por parte del Gobierno, para transitar por el escenario incierto de esta crisis sanitaria sin precedentes, ya se puede atisbar que la recuperación económica será larga y dificultosa, sobre todo desde el prisma de las relaciones laborales. El presente artículo hace un repaso de las principales medidas normativas adoptadas sobre el mercado de trabajo, pero sobre todo aborda los pormenores de la actuación de los servicios de prevención de riesgos laborales durante esta situación, esperemos transitoria. Por último, se centra en el tratamiento que se ha de dispensar a los trabajadores especialmente sensibles a la exposición por coronavirus, los cuales también deberán pasar a situación de incapacidad temporal, con la prestación económica correspondiente al accidente laboral, previo estudio del área sanitaria del servicio de prevención.

Palabras clave: COVID-19, prevención de riesgos laborales, servicios de prevención, crisis sanitaria, trabajadores especialmente sensibles, Coronavirus, SARS-CoV-2.

\section{ABSTRACT}

The emergence of COVID-19 has not only shaken the world of work, but it also transcends all dimensions that are known of. It has barely been two months since the state of alarm was declared by the Government, to travel through the uncertain scenario of this unprecedented health crisis, and it can already be seen that the economic recovery will be long and difficult, especially in the field of labor relations. This article reviews the main regulatory measures adopted on the labor market, but its main focus will be on addressing the details of the performance of the occupational risk prevention services during this situation, hopefully transitory. Finally, the article will shed some light on the treatment to be given to workers especially, those who are more affected by the Coronavirus, who must also go into a situation of temporary unemployment, as well as the financial benefit they are entitled to receive, after studying the health area concerned with the prevention service.
\end{abstract}

Keywords: COVID-19, occupational risk prevention, prevention services, Coronavirus, SARS-CoV-2.

\footnotetext{
* Correspondencia a: Rubén López Fernández. c/ Francisco Hernández Vidal, 7, 30500-Molina de Segura, Murcia (España) - ruben. lopez1@um.es - https://orcid.org/0000-0002-0152-5840

Cómo citar: López Fernández, Rubén. (2020). "Los servicios de prevención de riesgos laborales en tiempos del coronavirus»; Lan Harremanak, 43, 202-215. (https://doi.org/10.1387/lan-harremanak.21714).

Recibido: 11 mayo, 2020; aceptado: 03 junio, 2020.

ISSN 1575-7048 - elSSN 2444-5819 / (C) 2020 UPV/EHU
} 


\section{Introducción}

El último día de 2019, la Comisión Municipal de Salud y Sanidad de Wuhan (en la provincia china de Hubei) informó de 27 casos de una neumonía de origen desconocido. Todos compartían un elemento común: la exposición a un mercado mayorista de marisco, pescado y otros animales vivos. El 7 de enero de 2020 se determinó, como agente causante, a un nuevo virus de la familia Coronaviridae, que daría en llamarse SARS-CoV-2. El 30 de enero, la Organización Mundial de la Salud (en adelante OMS) declaró la emergencia de salud pública de importancia internacional, y el 11 de marzo la pandemia internacional. Sin ánimo de ahondar con exhaustividad en esta cronología, bastará decir que la del COVID-19 es la crisis más letal a la que se ha enfrentado la humanidad en casi un siglo, y que decenas de instituciones, nacionales y supranacionales ${ }^{1}$, vienen siguiendo con rigor su propagación para publicar regularmente instrumentos informativos y recursos con los que hacerle frente de manera global. En comunicación constante con estos organismos, y siguiendo sus directrices, los Ministerios de Sanidad y de Trabajo están alumbrando cuantiosos Documentos técnicos para los profesionales, los cuales están en actualización permanente, así como documentos informativos dirigidos a la población en general. Algunos de ellos serán referidos aquí.

Se trata, pues, de una situación sin precedentes a escala mundial. En un cortísimo espacio de tiempo se está asistiendo a situaciones inéditas, y a una concatenación de respuestas y medidas insólitamente novedosa. Como ejemplo, puede referirse la prohibición más estricta que haya adoptado nunca el Consejo Europeo, cuando el 17 de marzo cerró las fronteras exteriores de la zona Schengen; o el acuerdo alcanzado un día antes entre la OMS y la Cámara de Comercio Internacional para una actuación conjunta, por el que esta última ponía a disposición de la lucha contra el virus su red de 45 millones de empresas.

En España se ha puesto en práctica un instrumento que sólo había sido utilizado una vez desde su entrada en vigor: el estado de alarma ${ }^{2}$. Ello con el propósito de gestionar la presente crisis sanitaria y por medio del RD 463/2020, de 14 de

\footnotetext{
1 Por ejemplo, la OMS, la Organización Internacional del Trabajo, el Centro Europeo para la Prevención y el Control de las Enfermedades o el Centro Canadiense de Seguridad y Salud en el Trabajo.

${ }_{2}^{2}$ Con apoyo en el art. 4.b) Ley Orgánica 4/1981, de 1 de junio, de los estados de alarma, excepción y sitio.

Ya se empleó en diciembre de 2010, para atenuar la situación generada de puesta en peligro del derecho fundamental a la libertad de circulación y movimiento (art. 19 Constitución), al abandonar los controladores aéreos civiles sus obligaciones. En contraposición a aquel suceso, en el que la afectación se circunscribió a las torres de control de los aeropuertos y a los centros gestionados por AENA (Aeropuertos Españoles y Navegación Aérea), el estado de alarma aún vigente afecta a todo el territorio nacional.
} 
marzo, que fue publicado por el BOE a última hora de ese mismo día. La norma despliega el paquete de medidas que viene afectando a la libertad de movimientos de todos los ciudadanos en múltiples facetas de la vida. De entre estas, aquí se hace ligera referencia a las medidas adoptadas sobre las relaciones laborales, que por lo pronto ponen negro sobre blanco la insuficiencia del ordenamiento existente para encarar esta crisis, tanto en la trinchera de la protección de la salud de las personas como en la del mantenimiento de la economía. Así las cosas, vuelve a atisbarse en el horizonte inmediato una destrucción de empleo similar a la de la crisis económica de 2008, una precarización del mismo en términos generales, y consecuencias harto demoledoras para los grupos sociales más desfavorecidos.

\section{Las relaciones laborales tras la declaración del estado de alarma}

La presente crisis sanitaria ha impactado en el mercado de trabajo español con una violencia desconocida hasta el momento. Las medidas de confinamiento y limitación de la actividad ${ }^{3}$ han puesto a la economía - y por extensión a las relaciones laborales — en un estado de "cuasi-hibernación» que ha derivado en caída de la demanda interna — fundamentalmente motivada por el descenso del consumo, aunque también por el de la inversión- así como en ausencia de producción de ciertos bienes y servicios que dieron en considerarse «no esenciales».

En el caso de España, el Gobierno viene actuando de forma escalonada, lo cual pone una dificultad ańadida a todo estudio que se pretenda emprender sobre las futuribles consecuencias económicas. Analizar o estimar esas implicaciones económicas en el medio plazo, dada la situación de incertidumbre de la propia evolución de la pandemia, obliga a reajustar continuamente todos los parámetros. Con todo, puede ya decirse que el paro registrado ha subido durante el primer mes de confinamiento todo lo remontado desde la salida de la anterior crisis económica ${ }^{4}$.

En lo que atañe a las medidas adoptadas sobre la normativa laboral para capear tan excepcional escenario ${ }^{5}$, cabe destacar que el art. 5 RD-Ley 8/2020 es-

3 RD-Ley 8/2020, de 17 de marzo, de medidas urgentes extraordinarias para hacer frente al impacto económico y social del COVID-19.

RD-Ley 10/2020, de 29 de marzo, por el que regula un permiso retribuido recuperable para las personas trabajadoras por cuenta ajena que no presten servicios esenciales, con el fin de reducir la movilidad de la población en el contexto de lucha contra el COVID-19.

4 Véase, por ejemplo, a Llorente Heras, Raquel (2020) «Impacto del COVID-19 en el mercado de trabajo: un análisis de los colectivos vulnerables», Documentos de trabajo (Instituto Universitario de Análisis Económico y Social), 2.

5 Para mejor conocimiento, puede leerse a Jalil Naji, Maiedah (2020) «Normativa laboral de excepción COVID-19 en España», Noticias CIELO, extra 0; o a Arastey Sahún, María Lourdes (2020) "Las relaciones laborales tras la declaración del Estado de Alarma por el Coronavirus», Diario La Ley, 9606. 
tablece el teletrabajo como opción preferente sin necesidad de acuerdo entre las partes ${ }^{6}$. El art. 25.1 de la misma norma agiliza el procedimiento para solicitar la prestación por desempleo a los afectados por un ERTE con motivo de la pandemia, eliminando el período de carencia exigido por el art. 269 LGSS7. También es de resaltar que el art. 5 RD-Ley 6/2020 asimile a accidente de laboral los contagios por COVID-19 — se produjeran o no con ocasión o por consecuencia del trabajo desempeñado-, así como los períodos de aislamiento por haber estado en contacto con casos ya confirmados, recibiendo, pues, ambas contingencias una prestación económica mayor ${ }^{8}$.

\section{La actuación de los servicios de prevención de riesgos laborales durante la crisis sanitaria}

En este contexto, el papel de los servicios de prevención de riesgos laborales (SPRL) está llamado generalmente a hacer de eslabón entre las autoridades sanitarias y sus empresas cliente, cooperando con las primeras en determinadas cuestiones - algunas de las cuales serán abordadas aquí- y proporcionando a las segundas una información actualizada de cuantas recomendaciones y documentos sean emitidos, para adaptar sus actividades a esta nueva y cambiante situación y siempre con el objeto de limitar los contagios. Como el contacto con el COVID-19 puede afectar a personal sanitario y no sanitario, es a las empresas a quienes corresponde evaluar el riesgo de exposición de sus trabajadores en función de la actividad y de las concretas tareas desempeñadas, siguiendo las directrices indicadas por el SPRL y en atención a lo pautado por las autoridades sanitarias.

En lo atinente al riesgo biológico en entornos laborales, las medidas de precaución se apoyan en el RD 664/1997, de 12 de mayo, sobre la protección de los trabajadores contra los riesgos relacionados con la exposición a agentes biológicos durante el trabajo. El Procedimiento de actuación para los servicios de prevención de riesgos laborales frente a la exposición al SARS-CoV-29 (Procedi-

6 En materia preventiva, el mismo precepto flexibiliza las obligaciones de evaluar los riesgos laborales y planificar la actividad preventiva que el art. 16 LPRL impone al empresario. En detrimento de ello, se permite realizar una «autoevaluación» a la propia persona trabajadora.

7 Trescientos sesenta días cotizados dentro de los seis años inmediatamente anteriores al hecho causante.

8 Se trata de calificaciones de carácter extraordinario, limitadas a la coyuntura actual, y aplicables de manera exclusiva a la prestación por incapacidad temporal. Otras prestaciones derivadas como la incapacidad permanente, la viudedad o la orfandad, siguen considerándose contingencia común.

9 Véase en www.mscbs.gob.es/profesionales/saludPublica/ccayes/alertasActual/nCov-China/ documentos/PrevencionRRLL_COVID-19.pdf 
miento), en función de las actividades realizadas y conforme a los mecanismos de transmisión del COVID-19, define los siguientes escenarios de riesgo ${ }^{10}$ :

— Exposición de riesgo: aquellas situaciones laborales en las que se puede producir un contacto estrecho con un caso posible, probable o confirmado de infección por el SARS-CoV-2, sintomático.

- Exposición de bajo riesgo: aquellas situaciones laborales en las que la relación que se pueda tener con un caso posible, probable o confirmado, no incluye contacto estrecho.

- Baja probabilidad de exposición: trabajadores que no tienen atención directa al público o, si la tienen, se produce a más de dos metros de distancia, o disponen de medidas de protección colectiva que evitan el contacto (mampara de cristal, separación de cabina de ambulancia, etc.).

Respecto de los equipos de protección individual (EPI), conforme a lo establecido por el RD 773/199711 , deberán estar certificados de acuerdo con el Reglamento (UE) 2016/425. Cuando mascarillas o guantes estén destinados a uso médico, para prevenir el contagio de una enfermedad en el paciente, deberán certificarse como productos sanitarios conforme al RD 1591/200912. A este punto, la recomendación general es usar EPI desechables que garanticen la máxima protección con la menor molestia posible para el usuario. El recién referido Procedimiento dedica sus anexos II y III a informar sobre la forma óptima de empleo de los EPI, determinada por el Instituto Nacional de Seguridad y Salud en el Trabajo. El anexo III, además, expone estrategias para optimizar el uso de mascarillas, guantes y ropa de protección. No se trata de una descripción exhaustiva de cuantos EPI podrían proteger frente a un riesgo biológico, sino de los adecuados para el personal «potencialmente expuesto en el manejo de las personas con sintomatología de infección por el coronavirus». En el anexo II se abordan aspectos de protección respiratoria, guantes y ropa de protección, protección ocular y facial, colocación y retirada de los EPI, desecho, almacenaje y mantenimiento. Después de su utilización, los EPI deben tratarse como elementos posiblemente contaminados y, por tanto, como un foco

10 Tabla 1. Escenarios de riesgo de exposición al coronavirus SARS-CoV-2 en el entorno laboral (actualizada a 30 de abril).

Se define como caso posible aquel que presenta infección respiratoria aguda leve sin criterio para realizar la prueba. Caso descartado es aquel cuyos resultados de laboratorio para SARS-CoV-2 han dado negativo. Se habla de caso probable cuando los resultados no son concluyentes, y se envían al Centro Nacional de Microbiología para su confirmación. Por último, cabe considerar caso confirmado al que cumple criterio de laboratorio para PCR de screening positiva y PCR de confirmación en un gen alternativo.

11 De 30 de mayo, sobre disposiciones mínimas de seguridad y salud relativas a la utilización por los trabajadores de equipos de protección individual.

12 De 16 de octubre, por el que se regulan los productos sanitarios. 
de riesgo. Así pues, una retirada inapropiada de los mismos podría provocar la exposición del profesional. En atención a esto, debe acometerse un protocolo de puesta y retirada de todos los EPI secuenciado y pormenorizado. Tras la retirada, los que sean desechables se depositarán en contenedores habilitados al efecto y recibir tratamiento como residuos biosanitarios clase III; los EPI no desechables serán lavados adecuadamente y conforme a la documentación técnica.

\begin{tabular}{|c|c|c|}
\hline Exposición de riesgo & Exposición de bajo riesgo & $\begin{array}{l}\text { Baja probabilidad } \\
\text { de exposición }\end{array}$ \\
\hline $\begin{array}{l}\text { Personal sanitario asistencial } \\
\text { y no asistencial que atiende } \\
\text { a una persona sintomática. } \\
\text { Técnicos de transporte sa- } \\
\text { nitario, si hay contacto di- } \\
\text { recto con la persona sinto- } \\
\text { mática trasladada. } \\
\text { Situaciones en las que no se } \\
\text { puede evitar un contacto es- } \\
\text { trecho en el trabajo con una } \\
\text { persona sintomática. }\end{array}$ & $\begin{array}{l}\text { Personal sanitario cuya ac- } \\
\text { tividad laboral no incluye } \\
\text { contacto estrecho con una } \\
\text { persona sintomática, por } \\
\text { ejemplo: } \\
\text { — Acompañantes para } \\
\text { traslado. } \\
\text { —Celadores, camilleros, } \\
\text { trabajadores de lim- } \\
\text { pieza. } \\
\text { Personal de laboratorio res- } \\
\text { ponsable de las pruebas de } \\
\text { diagnóstico virológico. } \\
\text { Personal no sanitario que } \\
\text { tenga contacto con mate- } \\
\text { rial sanitario, fómites o de- } \\
\text { sechos posiblemente con- } \\
\text { taminados. } \\
\text { Ayuda a domicilio de con- } \\
\text { tactos asintomáticos. }\end{array}$ & $\begin{array}{l}\text { Trabajadores sin atención } \\
\text { directa al público, o a más } \\
\text { de } 2 \text { metros de distancia, o } \\
\text { con medidas de protección } \\
\text { colectiva que evitan el con- } \\
\text { tacto, por ejemplo: } \\
\text { - Personal administrativo. } \\
\text { - Técnicos de transporte } \\
\text { sanitario con barrera co- } \\
\text { lectiva, sin contacto di- } \\
\text { recto con el paciente. } \\
\text { - Conductores de trans- } \\
\text { portes públicos con ba- } \\
\text { rrera colectiva. } \\
\text { - Personal de seguridad. }\end{array}$ \\
\hline
\end{tabular}

Requerimientos

En función de la evaluación específica del riesgo de exposición de cada caso: componentes de EPI de protección biológica y, en ciertas circunstancias, de protección frente a aerosoles y frente a salpicaduras.
En función de la evaluación específica del riesgo de cada caso: componentes de EPI de protección biológica.

\section{No necesario uso de EPI.}

En ciertas situaciones (falta de cooperación de una persona sintomática):

- protección respiratoria, - guantes de protección. 
El Procedimiento además expone a los SPRL directrices en materia de trabajadores especialmente sensibles (en adelante TES), estudio y manejo de contactos, o colaboración en la gestión de la incapacidad temporal ${ }^{13}$. En atención a este último aspecto, el servicio sanitario de los SPRL tiene la obligación de elaborar un informe para que quede acreditada la situación susceptible y remitirlo a los servicios de atención primaria — si bien el procedimiento difiere ligeramente según la Comunidad Autónoma-, que son quienes se encargan de su tramitación. A este respecto, el Procedimiento considera situaciones susceptibles del tratamiento anterior:

1. Los casos confirmados que requieran las autoridades sanitarias.

2. Los casos posibles, probables y los contactos estrechos con casos posibles, probables o confirmados ocurridos en la empresa.

3. Los trabajadores especialmente sensibles en relación al SARS-Cov-2, siempre que no sea posible su reubicación o la adaptación de su puesto $^{14}$.

El anexo I del Procedimiento aporta a los SPRL dos formatos de informe para la comunicación de estas circunstancias: uno para los casos posibles, probables, confirmados o de contacto estrecho, y otro para trabajadores especialmente sensibles. Asimismo, tienen que informar de la obligatoriedad del aislamiento preventivo, de que la remisión de los partes tiene que hacerse sin la presencia del trabajador afectado, y de que, aun siendo vehiculados por los canales de la enfermedad común, el INSS procederá de forma interna a convertirlos en accidente de trabajo a efectos de la prestación económica a que den lugar.

Al margen de lo anterior, los SPRL tienen la obligación de informar y formar a los trabajadores que le requieran sus empresas cliente —así como de asesorar a estas últimas_-, sobre las medidas higiénicas a acometer tanto de carácter personal como para los lugares de trabajo, en relación a los riesgos de exposición al virus. La empresa debe informar adecuadamente - y recoger formato firmado por cada trabajador - de las recomendaciones emitidas por los Ministerios de Sanidad y de Trabajo en la materia; también de los pasos a seguir en caso de presentar síntomas compatibles con la enfermedad. El SPRL facilitará a las empresas los formatos de información referidos, y cartelería difundida por diversas instituciones sobre las buenas costumbres a seguir mientras dure la crisis sanitaria. Paralelamente, el SPRL hará llegar a los trabajadores, de manera no presen-

13 En las Instrucciones aclaratorias relativas al nuevo procedimiento de remisión de partes de los Servicios Públicos de Salud por coronavirus, el INSS establece que son los médicos del Servicio Público de Salud los que deben emitir los partes de baja y alta en los casos de afectación por COVID-19, tanto en las situaciones de contagio como en las de aislamiento, así como a todos los trabajadores que por su situación clínica lo necesiten, sean personal sanitario o no.

14 Aspecto que será abordada en el punto 3 del presente texto. 
cial, un manual de prevención específico sobre el coronavirus SARS-CoV-2 y un test cuyo contenido será el tratado en dicho manual ${ }^{15}$.

\section{La gestión de las personas especialmente vulnerables y los trabajadores especialmente sensibles al SARS-CoV-2}

Como se sabe, los SPRL tienen obligación de asesorar y asistir técnicamente a sus empresas cliente, a los trabajadores de estas y a sus representantes, sobre los aspectos relativos a la interrelación entre salud y trabajo. A este respecto, una de sus atribuciones clave es la de identificar a los denominados trabajadores especialmente sensibles frente a determinado riesgo, siendo en estos momentos la exposición al COVID-19 uno de los más evidentes. Esta tarea deben llevarla a acabo los profesionales sanitarios de los SPRL, que la desempeñarán identificando y evaluando este riesgo en las empresas concretas, al tiempo que valorando las condiciones de salud de cada trabajador. En relación a estos trabajadores especialmente sensibles al virus, se emite un informe con recomendaciones sobre las medidas específicas de prevención, adaptación y protección a acometer, en aras de alcanzar unas condiciones que permitan realizar el trabajo sin que el estado psicofísico de la persona en cuestión incorpore un riesgo sobreañadido a la posible exposición.

Con las evidencias científicas disponibles por el Ministerio de Sanidad a la fecha de este texto, se consideran grupos vulnerables de riesgo frente al COVID-19 a las personas con diabetes, enfermedad cardiovascular —incluida la hipertensión-, enfermedad pulmonar crónica, inmunodeficiencia, cáncer en fase de tratamiento activo, mayores de 60 años y mujeres embarazadas. En

15 En lo que atañe a estas obligaciones, empresa y SPRL pueden servirse de los numerosos instrumentos informativos que han ido apareciendo en materia, los cuales abordan cuestiones (algunas ya referidas aquí) como medidas higiénicas u organizativas; protección individual; protocolos a seguir frente a casos confirmados, probables, posibles o contactos; formación e información; desplazamientos; o gestión de residuos. Sin ánimo de exhaustividad, se refieren los siguientes: Buenas prácticas en los centros de trabajo (www.lamoncloa.gob.es/serviciosdeprensa/notasprensa/presidencia/ Documents/2020/GUIACEN TROSTRABAJOCOVID19b.pdf), Medidas preventivas generales para garantizar la separación entre trabajadores frente a COVID-19 (file://C:/Users/Ruben/AppData/Local/Packages/Microsoft.MicrosoftEdge_8wekyb3d8bbwe/TempState/Downloads/MEDIDAS\%20 PREVENTIVAS \% 20 GENERALES \% 20 PARA \% 20 GARANTIZAR \% 20 LA \% 20 SEPARACIÓN\%20ENTRE\%20TRABAJADORES\%20FRENTE\%20A\%20COVID-19\%20(1). pdf), Guía de actuación en materia preventiva por causa del COVID-19 en las obras de construcción (www.prevencionintegral.com/actualidad/noticias/2020/04/10/guia-actuacion-en-materia-preventiva-por-causa-covid-19-en-obras-construccion); o Guia de actuación en materia preventiva por causa del COVID-19 en las actividades del sector del metal (www.aecim.org/wp-content/uploads/2020/04/ Guia-COVID-19-METAL.pdf?utm_medium=email \&utm_campaign=AECIM\%20 Laboral\&utm_content=AECIM\%20Laboral+CID_9d7f4abeb1cec399e36011cae2963ded\&utm_ source=Email\%20marketing\&utm_term=Gua\%20preventiva). 
cuanto a estos trabajadores, el área sanitaria del SPRL debe estudiar sus características personales, su estado biológico y psicológico conocido, o que se pueda conocer, considerando el resultado de la evaluación de riesgos actualizada, los criterios de especial sensibilidad y, conforme a estos, determinar las medidas de prevención y protección que se estimen necesarias. Y es que no ha de perderse de vista el art. 25 LPRL, que en su punto 1 establece que estos trabajadores:

... no serán empleados en aquellos puestos de trabajo en los que, a causa de sus características personales, estado biológico o por su discapacidad física, psíquica o sensorial debidamente reconocida, puedan ellos, los demás trabajadores u otras personas relacionadas con la empresa ponerse en situación de peligro o, en general, cuando se encuentren manifiestamente en estados o situaciones transitorias que no respondan a las exigencias psicofísicas de los respectivos puestos de trabajo.

Lo cual no es óbice para que, antes de tramitar sus bajas por incapacidad temporal, se intente adaptar sus puestos de trabajo o reubicarlos en otros carentes de riesgo.

A propósito de esto, el Criterio para la gestión de personas especialmente vulnerables y trabajadores/as especialmente sensibles frente al SARS-CoV-2 en las empresas de Cataluña en el contexto de pandemia ${ }^{16}$ hace una distinción entre ambos conceptos. Las personas especialmente vulnerables (PEV) podrían definirse como aquellas que presentan factores de riesgo relacionados con su estado de salud que pueden incrementar, en base a criterios epidemiológicos y clínicos, la probabilidad de desarrollar el COVID-19 o presentar una evolución clínica desfavorable en caso de padecerlo. Las PEV, a juicio del documento, requieren en cualquier caso una atención específica por parte de empresa y SPRL, para adecuar la protección o las condiciones de trabajo más allá del nivel otorgado a la generalidad de los trabajadores. Ya se sabe que los TES son aquellos que "por sus propias características personales o estado biológico conocido, incluidos aquellos que tengan reconocida la situación de discapacidad física, psíquica o sensorial» hayan de considerarse especialmente vulnerables a los riesgos presentes en su actividad laboral. Asumiendo lo anterior, ser considerado PEV en relación con el coronavirus no significa automáticamente ser calificado como TES conforme al art. 25 LPRL. El matiz que les separa es el «riesgo laboral» al que tiene que estar expuesto el sujeto, y del cual la empresa lo debe proteger en aplicación de los preceptos de la LPRL y del RD 664/1997. La iniciativa de valorar a una PEV como posible TES frente al COVID-19 corresponde a la empresa, vía SPRL; pero también puede requerirlo el propio trabajador.

\footnotetext{
16 Associació Catalana de Salut Laboral (2020) «Criterio para la gestión de personas especialmente vulnerables y trabajadores/as especialmente sensibles frente al SARS-CoV-2 en las empresas de Cataluña en el contexto de pandemia", Archivos de Prevención de Riesgos Laborales, 8 de abril.
} 
El referido documento expone una tabla elaborada apoyándose en orientaciones y recomendaciones de diversas instituciones sanitarias. Entre otras, el Departament de Salut de Cataluña, el Ministerio de Sanidad, el European Centre for Disease Prevention and Control, o los Centers for Disease Control and Prevention. Se trata de una tabla sencilla y no cerrada, con el objeto de ayudar al personal médico a valorar cada caso, y que incluye: mayores de 65 años, mayores de 50 años asociados a comorbilidad, enfermedades cardíacas, enfermedades respiratorias crónicas, enfermedades endocrinológicas graves o descompensadas, obesidad mórbida, neoplasias con tratamiento activo, inmunodeficiencia e inmunosupresión, enfermedades digestivas crónicas graves, enfermedades hepáticas crónicas graves, enfermedades renales crónicas graves, embarazos, y trastornos psiquiátricos graves. La tabla y sus recomendaciones se refieren a las personas en general, y contrasta con los colectivos vistos para ser considerado TES, más reducidos.

$\mathrm{Al}$ margen del listado anterior - al que poca relevancia jurídica cabe darle por el momento, más allá de prestarles una atención más intensa desde el punto de vista preventivo-, se puede considerar como muy probable TES a las personas pertenecientes a alguno de los grupos considerados por el Ministerio de Sanidad —enumerados en la página anterior-, que ocupen un puesto de trabajo para el que la evaluación de riesgos considere que existe peligro de exposición y para el que las medidas preventivas adoptadas no hayan podido garantizar un control total del riesgo. Respecto de ellos, la empresa debe adoptar medidas específicas, de acuerdo a su especial sensibilidad, para eliminar la exposición: organizativas, técnicas, formación e información, EPI, etc. En caso de no ser ello posible, ni reubicarlos en otros puestos libres de riesgo — priorizando la posibilidad del teletrabajo-, debe elaborarse mediante el área sanitaria del SPRL un informe pormenorizado de su condición de salud, que será remitido al médico de atención primaria del trabajador de manera no presencial para ser tramitada su baja por incapacidad temporal por parte del servicio de salud público.

En el caso concreto de la trabajadora gestante, se considera poco probable que su estado represente un incremento en el riesgo de contagio o, caso de contagiarse de COVID-19, experimentar un cuadro clínico grave. En cuanto a la transmisión hereditaria, tampoco hay elementos para concluirla en mujeres infectadas durante el tercer trimestre de embarazo ${ }^{17}$. Con todo, y dado lo que supone una maternidad, parece que las autoridades sanitarias han preferido aplicar el principio de la precaución.

17 Investigadores chinos no encontraron evidencias de transmisión vertical en un grupo de nueve embarazadas con diagnóstico confirmado de COVID-19. Véase Chen, Huijun (2020) «Clinical characteristics and intrauterine vertical transmission potential of COVID-19 infection in nine pregnant women: a retrospective review of medical records", Lancet, 395. 
Capítulo aparte merecería, en el escenario presente, la actuación preventiva para los profesionales sanitarios ${ }^{18}$. En una crisis de transmisión comunitaria sostenida como esta es imprescindible que el sistema sanitario pueda mantener la capacidad de respuesta para asegurar la continuidad de la asistencia al flujo de pacientes en los hospitales, Por tanto, conviene insistir en la importancia de que todos los profesionales sanitarios actúen escrupulosamente conforme a las indicaciones de precaución ante cualquier paciente con síntomas respiratorios, con el objeto siempre de minimizar las exposiciones. Se considera, a todos los efectos, profesional sanitario a todos aquellos que figuran en la Ley 44/2003 ${ }^{19}$.

El manejo de casos en esta rama de la actividad — la más expuesta y a la vez la más crucial frente a la pandemia - puede sintetizarse en lo que se va a exponer aquí. A los trabajadores que presenten síntomas, aunque sean leves, se les indicará que contacten con el SPRL. Los clasificados como posibles, probables o confirmados, se retirarán de la actividad laboral y permanecerán aislados en sus domicilios recibiendo un tratamiento diferente según se esté ante un caso leve con aislamiento domiciliario o un caso grave que acabó requiriendo ingreso hospitalario. En el primer supuesto se realiza una PCR para finalizar el aislamiento. Para ello deben transcurrir 7 días desde el inicio de los síntomas, haber ausencia de fiebre sin necesidad de toma de antitérmicos y mejoría clínica respiratoria en los 3 días anteriores. Si la PCR es negativa y el trabajador se reincorpora a su actividad asistencial, deberá hacerlo con mascarilla quirúrgica hasta completar los 14 días desde el inicio de los síntomas, evitando además el contacto con personas vulnerables a esta enfermedad; si la PCR es positiva, continuará el aislamiento hasta que el resultado sea negativo aviniéndose al protocolo marcado por cada Comunidad Autónoma.

Si el caso requirió ingreso hospitalario, por haber presentado un cuadro clínico grave, podrán recibir el alta hospitalaria cuando su situación lo permita, y aunque su PCR siga siendo positiva. No obstante, deberán mantener aislamiento domiciliario monitorizado al menos 14 días desde el alta, y siempre que haya bajado la fiebre y hayan transcurrido 3 días desde la resolución de los síntomas.

Los contactos en el ámbito sanitario se manejan en función del tipo de exposición:

1. Un contacto casual con caso probable o confirmado de COVID-19 sin EPI, continuará con su actividad asistencial normal y se realizara vigilancia pasiva de síntomas.

18 Sobre el tema puede verse, por ejemplo, la Guía de actuación frente a COVID-19 en los profesionales sanitarios y socio-sanitarios, elaborada por el Ministerio de Sanidad, y cuya última actualización a la fecha en que se escriben estas líneas data del pasado 13 de abril: www.mscbs.gob.es/ profesionales/saludPublica/ccayes/alertasActual/nCov-China/documentos/Protocolo_Personal_ sanitario_COVID-19.pdf.

19 De 21 de noviembre, de ordenación de las profesiones sanitarias. 
2. Igual tratamiento se dará a un contacto estrecho con caso posible, probable o confirmado de COVID-19 con uso adecuado de EPI.

3. Un contacto estrecho con caso posible, probable o confirmado de COVID-19 sin EPI, recibirá un tratamiento diferente según se valore como una exposición de bajo o de alto riesgo. De ser considerada la exposición como de bajo riesgo, se continuará con la actividad normal y se hará vigilancia pasiva. De ser considerada como de alto riesgo, se retirará al profesional de la actividad y se realizará un test diagnóstico por PCR. $\mathrm{Si}$ el test da negativo se le reincorporará a la actividad, garantizando el uso de mascarilla quirúrgica y guantes en la asistencia y siguiendo vigilancia activa de la posible aparición de síntomas. Si el test da positivo, se iniciará el procedimiento de manejo de casos confirmados anteriormente descrito. De no habérsele podido realizar el test diagnóstico por PCR, se realizará cuarentena domiciliaria durante 14 días con vigilancia activa de síntomas.

Cualquiera de los supuestos anteriores, caso de desarrollar síntomas, se deben notificar al servicio de salud laboral, SPRL o servicio de medicina preventiva del hospital o al 112, para iniciar el procedimiento de manejo de casos conforme a lo establecido en la Comunidad Autónoma.

Los casos confirmados deben comunicarse urgentemente al servicio de salud pública de la Autonomía correspondiente, que los notificará al Centro de Coordinación de Alertas y Emergencias Sanitarias, del Ministerio de Sanidad, y al Centro Nacional de Epidemiología, según lo establecido en cada momento.

\section{Conclusiones}

En los primeros compases del estado de alarma, se asistió a diversos desbarajustes institucionales que vinieron en buena medida motivados por la novedad del enemigo. Desde el prisma de los SPRL, cabe hablar de la incertidumbre respecto a si la exposición al COVID-19 se debía considerar un riesgo grave e inminente, muy ligada tal cuestión a si esta era un riesgo laboral o no ${ }^{20}$.

${ }^{20}$ Ello fue generado por la cascada de denuncias recibidas por la Inspección de Trabajo por parte trabajadores que entendían tal cosa. Muchos funcionarios actuantes de la propia Inspección, así como las Autoridades Laborales de las distintas Comunidades Autónomas — que tienen atribuida la competencia de paralizar los trabajos en tales casos- no sabían a qué atenerse. El criterio fue que tal exposición no se consideraba riesgo laboral y, por ende, tampoco riesgo grave e inminente susceptible de propiciar una paralización en los trabajos. Sí se estaba (y se está) ante un riesgo laboral en el caso de los trabajos sanitarios, pero en cuanto a las actuaciones pertinentes se descartaba la paralización de la actividad por riesgo grave e inminente, pues, mientras dure el estado de alarma se ha de entender que el interés general y el derecho a la salud de la población está por encima de la integridad del tra- 
También se observó cierta descoordinación en la tramitación como incapacidad temporal de los trabajadores especialmente sensibles al virus. Durante los primeros días - incluso semanas - del estado de alarma, algunos médicos de cabecera desconocían ser quienes habían de recibir el informe de riesgo elaborado por el SPRL, para dar traslado de tal situación al órgano del servicio público de salud habilitado al efecto. El hecho de que el procedimiento sea distinto según la Comunidad Autónoma en cuestión, pudo tener mucho que ver.

Se seguirán produciendo, indudablemente, constantes intervenciones normativas del poder ejecutivo durante lo que se ha dado en llamar «desescalada» ${ }^{21}$. En cada una de sus fases, los SPRL deberán informar a sus empresas cliente sobre los protocolos a seguir para la reapertura de sus actividades y la adaptación a una nueva normalidad, en la medida en que el COVID-19 lo permita.

En lo que se espera sea el principio de una salida progresiva de esta crisis, se atisba una situación económica nada alentadora, con altos costes para la clase trabajadora (desempleo, precariedad laboral, exposición al virus durante la prestación de servicios en mayor o menor medida) y dificultades desconocidas para el tejido empresarial. Con todo, se seguirán con atención los nuevos acontecimientos de este escenario cambiante, para afrontar en las mejores condiciones posibles esta crisis sanitaria y social sin precedentes.

\section{Bibliografía}

Arastey Sahún, María Lourdes (2020). «Las relaciones laborales tras la declaración del Estado de Alarma por el Coronavirus", Diario La Ley, 9606.

Associació Catalana de Salut Laboral (2020). "Criterio para la gestión de personas especialmente vulnerables y trabajadores/as especialmente sensibles frente al SARSCoV-2 en las empresas de Cataluña en el contexto de pandemia», Archivos de Prevención de Riesgos Laborales, 8 de abril.

Confederación Española de la Pequeña y Mediana Empresa (2020). Guía de actuación en materia preventiva por causa del COVID-19 en las actividades del sector del metal (www.aecim.org/wp-content/uploads/2020/04/Guia-COVID-19-METAL.pdf?utm_ medium $=$ email\&utm_campaign=AECIM\%20Laboral\&utm_content=AECIM\%20 Laboral+CID_9d7f4abeb1cec399e36011cae2963ded\&utm_source=Email\%20 marketing\&utm_term=Gua\%20preventiva).

bajador en cuestión, siendo el sector sanitario el servicio esencial por antonomasia. Así las cosas, se podría proceder a corregir, reducir o suspender parcialmente la actividad, pero no a paralizarla.

A más abundamiento, véase la Resolución del Director del Organismo Estatal de la Inspección de Trabajo y Seguridad Social, de 20 de marzo del año presente, sobre la organización del organismo para la gestión de la crisis del COVID-19.

21 Proyectada por la Orden SND/388/2020, de 3 de mayo, por la que se establecen las condiciones para la apertura al público de determinados comercios y servicios, y la apertura de archivos, así como para la práctica del deporte profesional y federado. Publicada por el BOE de 3 de mayo. 
Confederación Nacional de la Construcción (2020). Guía de actuación en materia preventiva por causa del COVID-19 en las obras de construcción (www.prevencion integral.com/actualidad/noticias/2020/04/10/guia-actuacion-en-materia-preventivapor-causa-covid-19-en-obras-construccion).

Jalil NAJi, Maiedah (2020). "Normativa laboral de excepción COVID-19 en España», Noticias CIELO, extra 0.

Llorente Heras, Raquel (2020). "Impacto del COVID-19 en el mercado de trabajo: un análisis de los colectivos vulnerables», Documentos de trabajo (Instituto Universitario de Análisis Económico y Social), 2.

Ministerio de Sanidad, Consumo y Bienestar Social (2020). Buenas prácticas en los centros de trabajo (www.lamoncloa.gob.es/serviciosdeprensa/notasprensa/presidencia/ Documents/2020/GUIACEN TROSTRABAJOCOVID19b.pdf).

Ministerio de Sanidad, Consumo y Bienestar Social (2020). Guía de actuación frente a COVID-19 en los profesionales sanitarios y socio-sanitarios (www.mscbs.gob.es/ profesionales/saludPublica/ccayes/alertasActual/nCov-China/documentos/Protocolo_ Personal_sanitario_COVID-19.pdf).

Ministerio de Trabajo y Economía Social (2020). Medidas preventivas generales para garantizar la separación entre trabajadores frente a COVID-19 (file://C:/Users/Ruben/ AppData/Local/Packages/Microsoft.MicrosoftEdge_8wekyb3d8bbwe/TempState/ Downloads/MEDIDAS\%20PREVENTIVAS\%20GENERALES\%20PARA\%20 GARANTIZAR\%20LA\%20SEPARACIÓN\%20ENTRE\%20TRABAJADORES \%20FRENTE\%20A\%20COVID-19\%20(1).pdf).

Ministerio de Trabajo y Economía Social (2020) Procedimiento de actuación para los servicios de prevención de riesgos laborales frente a la exposición al SARS-CoV-2 (www.mscbs.gob.es/profesionales/saludPublica/ccayes/alertasActual/nCov-China/ documentos/PrevencionRRLL_COVID-19.pdf). 